\title{
Imaging Neuroinflammation in Alzheimer's Disease with Radiolabeled Arachidonic Acid and PET
}

\begin{abstract}
Giuseppe Esposito $^{1}$, Giampiero Giovacchini ${ }^{1,2}$, Jeih-San Liow ${ }^{1,3}$, Abesh K. Bhattacharjee ${ }^{1}$, Dede Greenstein ${ }^{4}$, Mark Schapiro ${ }^{1,5}$, Mark Hallett ${ }^{6}$, Peter Herscovitch ${ }^{7}$, William C. Eckelman ${ }^{7,8}$, Richard E. Carson ${ }^{7,9}$, and Stanley I. Rapoport ${ }^{1}$

${ }^{1}$ Brain Physiology and Metabolism Section, National Institute on Aging, National Institutes of Health, Bethesda, Maryland; ${ }^{2}$ Center for Molecular Bioimaging, University of Milano-Bicocca, Milan, Italy; ${ }^{3}$ Molecular Imaging Branch, National Institute of Mental Health, National Institutes of Health, Bethesda, Maryland; ${ }^{4}$ Child Psychiatry Branch, National Institute of Mental Health, National Institutes of Health, Bethesda, Maryland; ${ }^{5}$ Department of Pediatric Neurology, Cincinnati Children's Hospital Medical Center, Cincinnati, Ohio; ${ }^{6}$ Human Motor Control Section, Medical Neurology Branch, National Institute of Neurological Disease and Stroke, National Institutes of Health, Bethesda, Maryland; ${ }^{7}$ Department of Positron Emission Tomography, Clinical Center, National Institutes of Health, Bethesda, Maryland; ${ }^{8}$ Molecular Tracer LLC, Bethesda, Maryland; and ${ }^{9}$ Yale PET Center, Yale School of Medicine, New Haven, Connecticut
\end{abstract}

Incorporation coefficients $\left(K^{*}\right)$ of arachidonic acid $(\mathrm{AA})$ in the brain are increased in a rat model of neuroinflammation, as are other markers of AA metabolism. Data also indicate that neuroinflammation contributes to Alzheimer's disease (AD). On the basis of these observations, $K^{*}$ for AA was hypothesized to be elevated in patients with AD. Methods: A total of 8 patients with $A D$ with an average $( \pm S D)$ Mini-Mental State Examination score of $14.7 \pm 8.4$ (mean age, $71.7 \pm 11.2 \mathrm{y}$ ) and 9 controls with a normal Mini-Mental State Examination score (mean age, $68.7 \pm 5.6$ y) were studied. Each subject received a ${ }^{15} \mathrm{O}$-water PET scan of regional cerebral blood flow, followed after 15 min by a $1-{ }^{11} \mathrm{C}-\mathrm{AA}$ scan of regional $K^{*}$ for AA. Results: In the patients with $A D$, compared with control subjects, global gray matter $K^{*}$ for $A A$ (corrected or uncorrected for the partial-volume error [PVE]) was significantly elevated, whereas only PVE-uncorrected global cerebral blood flow was reduced significantly $(P<0.05)$. A false-discovery-rate procedure indicated that PVE-corrected $K^{\star}$ for AA was increased in 78 of 90 identified hemispheric gray matter regions. PVE-corrected regional cerebral blood flow, although decreased in 12 regions at $P<0.01$ by an unpaired $t$ test, did not survive the false-discovery-rate procedure. The surviving $K^{*}$ increments were widespread in the neocortex but were absent in caudate, pallidum, and thalamic regions. Conclusion: These preliminary results show that $K^{*}$ for $\mathrm{AA}$ is widely elevated in the AD brain, particularly in regions reported to have high densities of senile (neuritic) plaques with activated microglia. To the extent that the elevations represent upregulated AA metabolism associated with neuroinflammation, PET with $1-{ }^{11} \mathrm{C}-\mathrm{AA}$ could be used to examine neuroinflammation in patients with $A D$ and other brain diseases.

Received Dec. 6, 2007; revision accepted May 12, 2008

For correspondence or reprints contact: Stanley I. Rapoport, Brain Physiology and Metabolism Section, Building 9, Room 1S128, National Institute on Aging, National Institutes of Health, Bethesda, MD 20892.

E-mail: sir@helix.nih.gov

COPYRIGHT @ 2008 by the Society of Nuclear Medicine, Inc.
Key Words: arachidonic; neuroinflammation; PET; Alzheimer's; imaging

J Nucl Med 2008; 49:1414-1421

DOI: 10.2967/jnumed.107.049619

$\mathbf{T}$ he postmortem Alzheimer's disease (AD) brain is characterized by intracellular neurofibrillary tangles with paired helical filaments consisting of phosphorylated $\tau$-protein and extracellular senile (neuritic) plaques containing $\beta$-amyloid fibrils. The senile plaques often are infiltrated by activated microglia that secrete inflammatory cytokines, release nitric oxide, and express peripheral benzodiazepine receptors $(1-4)$.

Inflammatory cytokines released from the microglia can bind to astrocytic cytokine receptors that are coupled to the $\mathrm{Ca}^{2+}$-dependent enzymes, cytosolic phospholipase $\mathrm{A}_{2}$ $\left(\mathrm{cPLA}_{2}\right)$, and secretory phospholipase $\left(\mathrm{sPLA}_{2}\right)(5)$. Each of these enzymes, when activated, hydrolyzes esterified arachidonic acid (AA) (20:4n-6) from membrane phospholipids. The released nitric oxide also can promote AA hydrolysis from the membrane by $\mathrm{cPLA}_{2}$, by stimulating glutamate release from nerve terminals and thereby increasing intracellular $\mathrm{Ca}^{2+}$ concentrations via postsynaptic ionotropic $N$-methyl-D-aspartate and other glutamatergic receptors (6-8). $\beta$-amyloid peptide in the AD brain also can provoke glutamate-induced excitotoxicity and $\mathrm{PLA}_{2}$ activation $(9,10)$. Consistent with this scenario, the AD brain demonstrates increased cytokine levels (3), increased expression of both $\mathrm{CPLA}_{2}$ and $\mathrm{sPLA}_{2}$, increased concentrations of inflammatory metabolites of AA $(5,11,12)$, and increased glutamatergic markers and different forms of accumulated $\beta$-amyloid $(9,10,13)$. Additionally, concentrations of iso- 
prostane and isoflurane metabolites of AA are elevated in cerebrospinal fluid (CSF) from patients with AD (14).

In view of these observations, AA metabolism is likely elevated in the $\mathrm{AD}$ brain; having a method to image this metabolism might help in examining neuroinflammation in the course and therapy of $\mathrm{AD}$. We have developed such a method. It involves injecting radiolabeled AA intravenously and then determining regional brain AA incorporation coefficients $\left(K^{*}\right.$; brain radioactivity normalized to integrated plasma radioactivity) using quantitative autoradiography in unanesthetized rodents or PET in nonhuman primates or humans. $K^{*}$ for AA represents metabolic loss of AA in the brain; once lost by metabolism, AA cannot be synthesized de novo nor can it be converted from its precursor, linoleic acid (18:2n-6) (15). $K^{*}$ for AA is unaffected by changes in regional cerebral blood flow ( $\mathrm{rCBF}$ ), which makes radiolabeled AA an ideal tracer for independently imaging brain AA metabolism (16-19).

We used the method described above to demonstrate an increased $K^{*}$ for AA in wide areas of the brain in unanesthetized rats in which bacterial lipopolysaccharide had been infused into the cerebral ventricles for $6 \mathrm{~d}$, a model of chronic neuroinflammation. The elevations were accompanied by increased brain expression of $\mathrm{cPLA}_{2}$, increased turnover rates of AA in brain membrane phospholipids, increased formation of AA-derived eicosanoids such as prostaglandin $\mathrm{E}_{2}$, and formation of activated microglia after a longer infusion time (20-23). Furthermore, the increments in $K^{*}$ after lipopolysaccharide infusion could be reduced by chronic pretreatment with lithium, which is reported to downregulate each of these markers of brain AA metabolism in control rats (24).

In this article, the fatty acid method with PET and intravenous $1-{ }^{11} \mathrm{C}$-AA was used to image $K^{*}$ for AA, as a marker of neuroinflammation, in diagnosed patients with $\mathrm{AD}$ and age-matched healthy controls. Methods for making measurements and calculations are reported elsewhere in detail $(17-19,25)$. PET and intravenous ${ }^{15} \mathrm{O}$-water also were used to image $\mathrm{rCBF}$ as a marker of brain functional activity in the same subjects (26) and to coregister AA scans to anatomic MRI scans for regional data analysis and for partial-volume error (PVE) correction.

\section{MATERIALS AND METHODS}

\section{Subject Selection}

The protocol was approved by the Institutional Review Board of the National Institute of Neurological Disorders and Stroke and by the Radiation Safety Committee of the National Institutes of Health. Eight otherwise healthy male patients with AD (mean age $\pm \mathrm{SD}, 71.1 \pm 11.2 \mathrm{y}$; range, 51-87 y) who met research criteria for $\mathrm{AD}$ and were mainly mildly to moderately (1 severely) demented on the Mini-Mental State Examination (mean score, $14.7 \pm 8.4$; range, 4-27) (27) were studied. In addition, 9 healthy age-matched male controls (mean age, 68.7 \pm 5.6; range, 60-76 y; mean Mini-Mental State Examination score, 30) were studied. Exclusion criteria included a history of head trauma, hypertension or other cardiovascular disorder, diabetes, alcoholism, psychiatric or neurologic disorder, or malignancy. AD and control subjects were normotensive and off centrally acting medication for at least $2 \mathrm{wk}$, aspirin for at least $2 \mathrm{~d}$, and caffeine and alcohol for at least $12 \mathrm{~h}$ before the procedure.

\section{PET Procedure}

$1-{ }^{11} \mathrm{C}-\mathrm{AA}$ was synthesized as reported $(17,28)$. The tracer was $97.6 \%$ pure on high-performance liquid chromatography, and its specific activity exceeded $3,700 \mathrm{MBq}(100 \mathrm{mCi}) / \mu \mathrm{mol}$.

Indwelling radial vein and artery catheters were inserted before scanning, and the subject's head was secured in a thermoplastic face mask fixed to the scanner bed. Scanning was performed with an Advance Tomograph (GE Healthcare), which acquires 35 simultaneous slices with $4.25-\mathrm{mm}$ separation and has in-plane and axial resolutions of 6-7 $\mathrm{mm}$. Scans were performed parallel to the orbitomeatal line and were conducted in a quiet, dimly lit room, with the subject's eyes open and ears unoccluded.

After a transmission scan had been performed for attenuation correction, $370 \mathrm{MBq}(10 \mathrm{mCi})$ of ${ }^{15} \mathrm{O}$-water was injected as an intravenous bolus to measure rCBF. A 60 -s scan was performed in the 3-dimensional mode after the bolus had reached the brain, and rCBF images were produced using the measured arterial input function (26). To quantify regional values of $K^{*}$ for AA and regional blood volumes, $\mathrm{V}_{\mathrm{b}}, 15 \mathrm{~min}$ after the ${ }^{15} \mathrm{O}$-water injection, $920 \pm 115 \mathrm{MBq}(24.9 \pm 3.1 \mathrm{mCi})$ of $1{ }^{11} \mathrm{C}-\mathrm{AA}$ was infused intravenously for $3 \mathrm{~min}$ at a constant rate. Serial dynamic 3-dimensional scans ( $30 \mathrm{~s}$ to $5 \mathrm{~min}$ ) were performed for $1 \mathrm{~h}$. Radial artery blood (1-3 mL) was sampled at fixed times, and radioactivity in whole blood and plasma was measured with a $\gamma$-counter. Details of the procedures have been published $(18,19)$.

\section{Motion Correction}

Subject motion during the 60-min acquisition period was corrected with a mutual information registration of each time frame to a standard frame before attenuation correction. On the basis of calculated motion, the transmission images were resliced and projected for final attenuation correction, reconstruction, and realignment.

\section{Plasma Time-Activity Curves}

Whole-blood and plasma radioactivities were determined as a function of time after injecting $1{ }^{11} \mathrm{C}-\mathrm{AA}$. In 7 of the 9 controls, a rapid extraction procedure $(18,29)$ was used to determine radioactivity due to $1-{ }^{11} \mathrm{C}$-AA and $1-{ }^{11} \mathrm{C}-\mathrm{CO}_{2}$. In all the patients with $\mathrm{AD}$ and in 2 of the controls, fractional metabolite measurements were not performed with this procedure. To analyze all PET scans together, therefore, the fractional data $\left(1-{ }^{11} \mathrm{C}-\mathrm{AA}\right.$ and $\left.1-{ }^{11} \mathrm{C}-\mathrm{CO}_{2}\right)$ from the 7 controls having appropriate input function data were averaged to obtain mean fractional curves, which then were used to process individual radioactivity curves in each patient with AD. The curves were multiplied by the group average fractional curve to produce time-activity curves of $1-{ }^{11} \mathrm{C}-\mathrm{AA}$ and $1-{ }^{11} \mathrm{C}-\mathrm{CO}_{2}$ in these patients and in the 2 remaining controls. To assess the effect of using average curves, data from the 7 controls also were analyzed with the averaged metabolite curves. $t$ tests showed that the results were not significantly affected by this procedure. To have a consistent statistical analysis, we therefore report data on all subjects processed with the averaged metabolite curves. 


\section{Modeling}

On a pixel-by-pixel basis, reconstructed images were analyzed using the following equation to produce parametric images of $K^{*}$ for AA (incorporation coefficient of plasma AA into brain tissue, $\mu \mathrm{L} / \mathrm{min} / \mathrm{cm}^{3}$ of brain) and of $\mathrm{V}_{\mathrm{b}}$ (cerebral blood volume, $[\mathrm{mL}$ of blood $] /\left[\mathrm{cm}^{3}\right.$ of brain $\left.]\right)$,

$$
\mathrm{C}_{\mathrm{i}}(\mathrm{t}-\Delta \mathrm{t})=\mathrm{V}_{\mathrm{b}} \mathrm{C}_{\mathrm{b}}(\mathrm{t})+\mathrm{K}^{*} \int_{0}^{\mathrm{t}} \mathrm{C}_{\mathrm{p}}(\mathrm{s}) \mathrm{ds}+\mathrm{C}_{\mathrm{CO} 2}(\mathrm{t})
$$

$\mathrm{C}_{\mathrm{i}}(\mathrm{t}), \mathrm{C}_{\mathrm{b}}(\mathrm{t})$, and $\mathrm{C}_{\mathrm{p}}(\mathrm{t})$ are pixel, whole-blood, and plasma $1-{ }^{11} \mathrm{C}-$ AA time-activity curves, respectively; $\mathrm{C}_{\mathrm{CO} 2}(\mathrm{t})$ is the predicted brain tissue concentration of ${ }^{11} \mathrm{C}-\mathrm{CO}_{2}$; and $\Delta \mathrm{t}$ is the delay between the brain and blood curves. The predicted tissue ${ }^{11} \mathrm{C}-\mathrm{CO}_{2}$ concentration was computed by measuring for each subject the plasma ${ }^{11} \mathrm{C}-\mathrm{CO}_{2}$ concentration and applying a 1-tissue-compartment model with published values of the gray matter influx rate constant $\left(K_{1}\right)$ and the distribution volume for $\mathrm{CO}_{2}(30)$. Calculations were applied to the original radioactivity images and to images that had been corrected for the PVE $(18,31)$.

\section{Registration to MR Images}

For each subject, $K^{*}$ images derived from the original PET volumes after $1-{ }^{11} \mathrm{C}$-AA injection were registered to the $\mathrm{CBF}$ volume to correct for motion between the $1{ }^{11} \mathrm{C}-\mathrm{AA}$ and ${ }^{15} \mathrm{O}-$ water scans, using a 6-parameter transformation and a mutual information cost function $(19,32)$. CBF and MRI volumes then were coregistered using the same algorithm. Images of $K^{*}$ for AA were transformed to MRI space using the product of the 2 transformation matrices.

\section{PVE Correction}

Brain radioactivity, corrected for the PVE, was calculated with a 3-compartment (gray matter, white matter, and CSF) MRI-based approach $(19,33)$. Binary mask images for gray matter $\left(\mathrm{m}_{\mathrm{GM}}\right)$, white matter $\left(\mathrm{m}_{\mathrm{WM}}\right)$, and $\mathrm{CSF}\left(\mathrm{m}_{\mathrm{CSF}}\right)$ first were produced using an adaptive fuzzy c-mean segmentation. The gray and white matter masks then were smoothed, based on a 3-dimensional gaussian kernel of 6-mm full width at half maximum that corresponded to the resolution of the scanner, to account for radioactivity spill-out and spill-in effects between gray and white matter and for spill-out of gray matter activity into CSF. White matter radioactivity was assumed uniform, and CSF radioactivity was set at zero. For each voxel, the PVE-corrected radioactivity was calculated as:

$$
\mathrm{C}_{3 \mathrm{~S}}=\left(\mathrm{C}-\mathrm{C}_{\mathrm{WM}} \mathrm{S}_{\mathrm{WM}}\right) / \mathrm{s}_{\mathrm{GM}},
$$

where $\mathrm{C}_{3 \mathrm{~S}}$ is PVE-corrected gray matter radioactivity, $\mathrm{C}$ is measured $\mathrm{PET}$ radioactivity, $\mathrm{C}_{\mathrm{WM}}$ is estimated white matter radioactivity, and $\mathrm{s}_{\mathrm{GM}}$ and $\mathrm{s}_{\mathrm{WM}}$ are smoothed masks for gray and white matter, respectively. $\mathrm{C}_{\mathrm{wm}}$ was calculated by an extrapolation method (19). For each frame, PET activity values of pixels with $\mathrm{s}_{\mathrm{wm}}$ values greater than 0.99 were identified and then fitted as a linear function of $\mathrm{s}_{\mathrm{wm}}$. The fitted value at $\mathrm{s}_{\mathrm{wm}}=1$ was used as $\mathrm{C}_{\mathrm{wm}}$.

\section{Image Processing for Statistical Analysis}

Individual $\mathrm{rCBF}$ images were aligned without smoothing to a stereotactic PET template using Statistical Parametric Mapping-2 software (http://www.fil.ion.ucl.ac.uk/spm/software) (19,34). The transformation information obtained by alignment was used to resample the $K^{*}$ images from the $1-{ }^{11} \mathrm{C}$-AA scans, after they had been aligned to the $\mathrm{CBF}$ image in the same stereotactic space. The same transformation information was used to resample the gray matter volume into the stereotactic space. Region-of-interest masks identifying 90 gray matter regions in the stereotactic space of the cerebral hemispheres (35), plus the resampled gray matter mask, then were applied to each subject's spatially normalized rCBF and $K^{*}$ images to obtain 90 (45 bilateral) weighted mean $\mathrm{rCBF}$ and $K^{*}$ for AA values, respectively. We used the gray matter mask to minimize mixing white matter values into the calculated region-of-interest measurements.

For each subject, global gray matter $\mathrm{rCBF}$ and global $K^{*}$ for AA were calculated by averaging the 90 bilateral regional hemispheric values of $\mathrm{rCBF}$ and $K^{*}$, respectively. Statistical comparisons were made between AD and control means. Data from an individual patient with $\mathrm{AD}$ were not matched to data from an exact-age control, as PVE-corrected $\mathrm{rCBF}, K^{*}$ for $\mathrm{AA}$, and regional glucose metabolism do not change with age in healthy nonhypertensive controls $(19,36)$, and the numbers of subjects were too limited to do this in any case. Group comparisons for global and PVE-corrected regional means were made using 2 -tailed $t$ tests. Additionally, a false-discovery-rate (FDR) procedure (37) was used to account for the increased risk of performing multiple comparisons. In this procedure, it was accepted that $5 \%$ of surviving differences between means were false-positives. The FDR procedure applies to statistically independent as well as to positively correlated data (38).

\section{RESULTS}

\section{Global Values of CBF and $K^{*}$ for AA}

Table 1 lists mean values of global gray matter $\mathrm{CBF}$ and $K^{*}$ for $\mathrm{AA}$ in the patients with $\mathrm{AD}$ and in control subjects, before and after a PVE correction. Without the correction, global CBF was reduced significantly by $28.6 \%$ in the patients with $\mathrm{AD}(n=6)$, compared with control subjects $(n=7)$, whereas global $K^{*}$ for AA was elevated significantly by $18.3 \%$ in the patients with $\operatorname{AD}(n=8)$, compared with control subjects $(n=9)$. There were fewer CBF than $K^{*}$ measurements because some of the CBF studies failed.

Because a PVE correction compensates for spill-out or spill-in effects by resolution and makes the measured tissue concentration approximate the true concentration (19), this correction increased global $\mathrm{CBF}$ and $K^{*}$ for AA. After the correction, differences between the patients with $\mathrm{AD}$ and controls remained significant for global $K^{*}(P<0.01)$ but not global CBF. PVE-corrected $K^{*}$ for AA was $26.4 \%$ higher in the patients with $\mathrm{AD}$ than in controls $(8.7 \pm 1.4$ $\mu \mathrm{L} / \mathrm{min} / \mathrm{cm}^{3}$, compared with $\left.6.9 \pm 0.8 \mu \mathrm{L} / \mathrm{min} / \mathrm{cm}^{3}\right)$.

\section{Comparison of Regional PVE-Corrected Values of rCBF and $K^{\star}$}

Two-tailed $t$ tests showed that PVE-corrected rCBF was less at $P<0.01$ in the patients with AD than in the control subjects in 12 of the 90 regions examined (data not shown). However, these regions, as well as the remaining 78, did not survive the FDR analysis. In contrast, 78 regions survived the FDR analysis for PVE-corrected global $K^{*}$ for AA, with all $K^{*}$ s being higher in the patients with $\mathrm{AD}$ than in control subjects (Table 2). Regions that survived were largely in the 
TABLE 1

Global Values of CBF and $K^{\star}$ for AA in Healthy Controls and Patients with AD, Before and After Correction for PVE

\begin{tabular}{|c|c|c|c|c|c|}
\hline \multirow[b]{2}{*}{ Group } & \multirow[b]{2}{*}{ Parameter } & \multicolumn{2}{|c|}{ PVE-uncorrected } & \multicolumn{2}{|c|}{ PVE-corrected } \\
\hline & & $\begin{array}{c}\text { CBF } \\
(\mathrm{mL} / 100 \mathrm{~g} / \mathrm{min})\end{array}$ & $\begin{array}{c}K^{\star} \\
\left(\mu \mathrm{L} / \mathrm{min} / \mathrm{cm}^{3}\right)\end{array}$ & $\begin{array}{c}\mathrm{CBF} \\
(\mathrm{mL} / 100 \mathrm{~g} / \mathrm{min})\end{array}$ & $\begin{array}{c}K^{\star} \\
\left(\mu \mathrm{L} / \mathrm{min} / \mathrm{cm}^{3}\right)\end{array}$ \\
\hline \multirow[t]{2}{*}{ Control } & Number ${ }^{\dagger}$ & 7 & 9 & 7 & 9 \\
\hline & $\begin{array}{l}\text { Mean } \pm \text { SD } \\
\text { CV }(\%)\end{array}$ & $\begin{array}{l}38.0 \pm 5.3 \\
13.8\end{array}$ & $\begin{array}{r}4.7 \pm 0.6 \\
12.0\end{array}$ & $\begin{array}{l}61.6 \pm 10.1 \\
16.4\end{array}$ & $\begin{array}{r}6.9 \pm 0.8 \\
11.9\end{array}$ \\
\hline \multirow[t]{2}{*}{$A D$} & Number ${ }^{\dagger}$ & 6 & 8 & 6 & 8 \\
\hline & $\begin{array}{l}\text { Mean } \pm \text { SD } \\
\text { CV (\%) }\end{array}$ & $\begin{array}{l}27.1 \pm 7.6^{\ddagger} \\
28.1\end{array}$ & $\begin{array}{r}5.5 \pm 0.8^{\ddagger} \\
15.2\end{array}$ & $\begin{array}{l}48.3 \pm 14.0 \\
28.9\end{array}$ & $\begin{array}{r}8.7 \pm 1.4 \S \\
15.7\end{array}$ \\
\hline Difference (\%) & & -28.6 & 18.3 & -21.5 & 26.4 \\
\hline \multicolumn{6}{|c|}{$\begin{array}{l}{ }^{*} \text { Differs significantly from control mean by } 2 \text {-tailed } t \text { test. } \\
{ }^{\dagger} \text { Number of CBF scans is fewer than } K^{\star} \text { scans because of failure of some CBF scans. } \\
{ }^{\ddagger} P \leq 0.05 \text {. } \\
{ }^{\S} P \leq 0.01 \text {. } \\
\text { Values were calculated from mean values from } 90 \text { hemispheric regions identified in stere }\end{array}$} \\
\hline
\end{tabular}

neocortex, hippocampus, and amygdala. About half of the 12 regions that did not survive the FDR analysis were subcortical and included the left thalamus, left and right pallidum, and left and right caudate nucleus (Table 3 ). These differences are illustrated in the serial horizontal brain slices of Figure 1.

\section{Normalized Regional Values of rCBF and $\boldsymbol{K}^{*}$ for AA}

After PVE-corrected $\mathrm{rCBF}$ was normalized to global PVE-corrected CBF, 7 group mean differences survived the FDR procedure. Reductions were noted in the right temporal inferior and middle gyri, the left precuneus, and the right supramarginal gyrus, whereas increases occurred in the left frontal superior medial gyrus, left putamen, and right thalamus. No group difference of normalized PVEcorrected $K^{*}$ for AA survived the FDR procedure.

\section{$\mathbf{V}_{\mathbf{b}}$}

Significant differences in $V_{b}$ (Eq. 1) between patients with $\mathrm{AD}$ and control subjects occurred in only a few regions and were not in a consistent direction (data not shown).

\section{DISCUSSION}

PET with intravenously injected $1-{ }^{11} \mathrm{C}-\mathrm{AA}$ was used to show that mean values of PVE-uncorrected and -corrected gray matter global hemispheric $K^{*}$ for AA were increased by $18 \%(P<0.05)$ and $26 \%(P<0.01)$, respectively, in otherwise healthy, mildly to moderately (1 severely) demented unmedicated patients with $\mathrm{AD}$, compared with agematched healthy controls. Of the 90 hemispheric regions studied (35), the FDR procedure showed that mean PVEcorrected regional $K^{*}$ for AA was elevated in 78 regions, largely in the cerebral cortex. The 12 regions in which PVE-corrected regional $K^{*}$ did not survive the FDR pro- cedure included right and left caudate, right and left pallidum, and left thalamus (Table 3; Fig. 1).

PVE-uncorrected but not PVE-corrected mean global CBF was significantly less $(26 \% ; P<0.05)$ in the patients with $\mathrm{AD}$ than in the control subjects (Table 1). Of the 90 regions examined, PVE-corrected $\mathrm{rCBF}$ was reduced at $P<0.01$ on a 2 -tailed $t$ test in 12 of them, but none of these reductions survived the FDR procedure. The procedure did indicate that PVE-corrected $\mathrm{rCBF}$, when normalized to the global CBF, was reduced in 4 regions and increased in 3 , of which 2 were the left putamen and right thalamus. Significant differences in $V_{b}$ between the 2 groups occurred in a few regions but were not in the same direction and were uninformative.

The mean PVE-corrected global gray matter CBF in the controls, $61.0 \pm 10.1$ (coefficient of variation $[\mathrm{CV}]=$ $16.4 \%$ ) $\mathrm{mL} / 100 \mathrm{~g} / \mathrm{min}$ (Table 1 ), is similar to a reported gray matter mean in older healthy subjects, $66(\mathrm{CV}=13 \%)$ $\mathrm{mL} / 100 \mathrm{~g} / \mathrm{min}$ (19). The mean PVE-corrected global $K^{*}$ for AA, $6.9 \pm 0.8(\mathrm{CV}=11.9 \%) \mu \mathrm{L} / \mathrm{min} / \mathrm{cm}^{3}$ (Table 1), corresponds to a published global gray matter mean, 7.03 $(\mathrm{CV}=8 \%) \mu \mathrm{L} / \mathrm{min} / \mathrm{cm}^{3}$, in older healthy subjects (19). Regional PVE-corrected means of $\mathrm{rCBF}$ and $K^{*}$ for $\mathrm{AA}$ also correspond to published values in healthy subjects.

The significant reduction in the mean global CBF uncorrected for the PVE (Table 1) also agrees with the literature (39), whereas the absence of a significant difference or of a difference that survived the FDR procedure in PVE-corrected CBF or rCBF, respectively, likely reflected the few subjects in which $\mathrm{rCBF}$ was measured, the high coefficient of variation of the flow measurements (Table 1), and noise introduced by the PVE correction (40).

The results support the hypothesis that regional $K^{*}$ for AA would be increased in patients with $\mathrm{AD}$, as a marker of upregulated AA metabolism accompanying neuroinflam- 


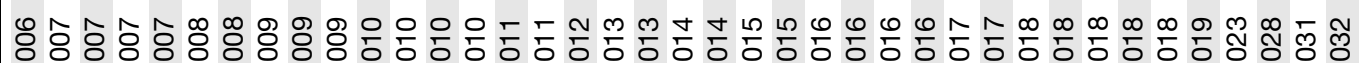

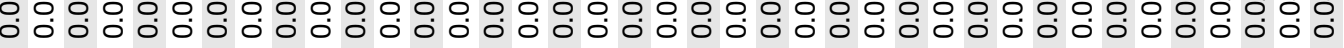

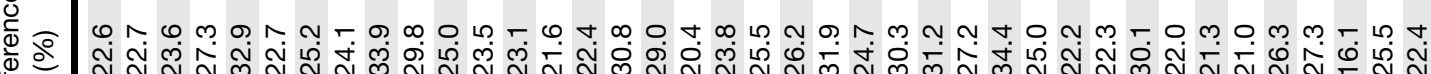
喜

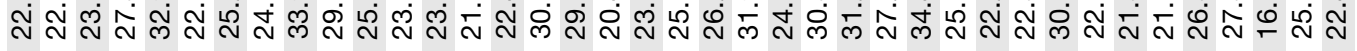

นำ

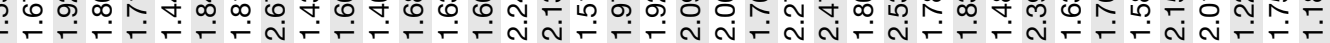

గু শ্র

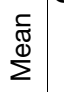

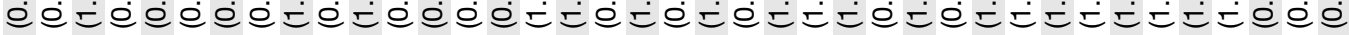
ฌ

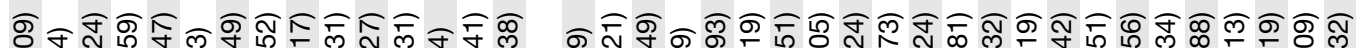

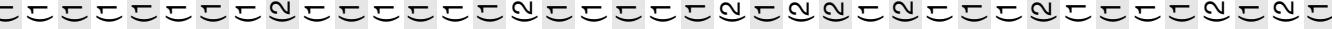
ల్ $5 \&$ o め बं

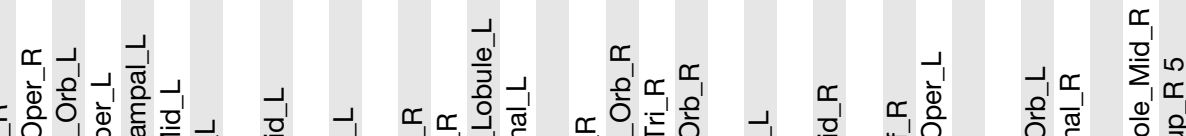

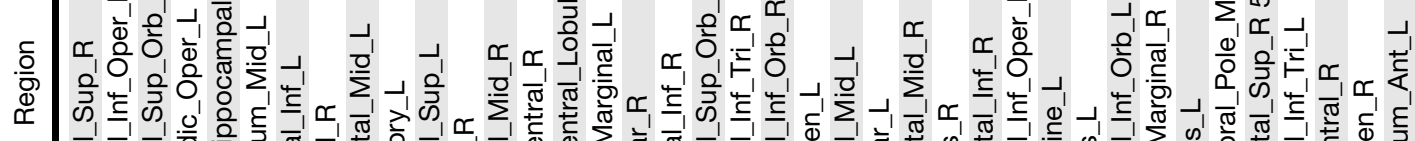

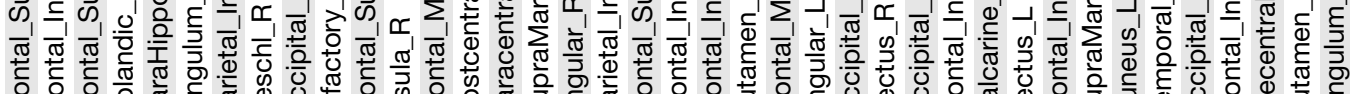

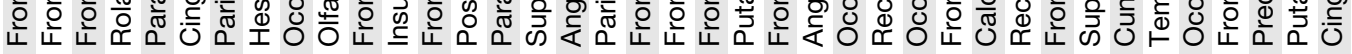

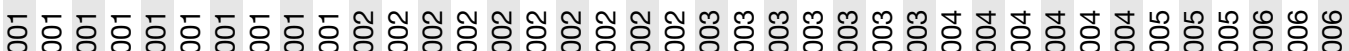

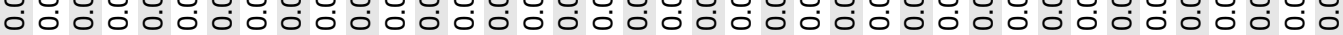

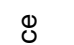

d 产 它

\section{$\stackrel{Ð}{\mathscr{0}}$ \\ 离}

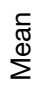

สำ

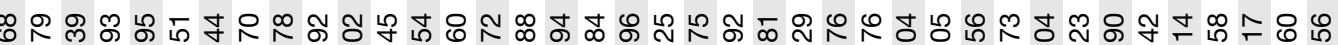
으응에 $\sum^{\infty}$

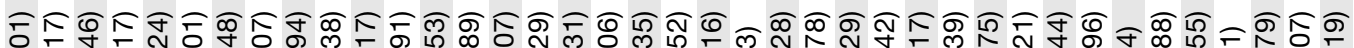

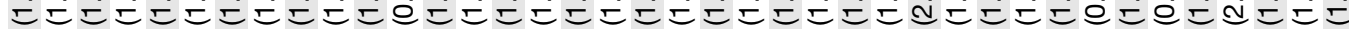
œ

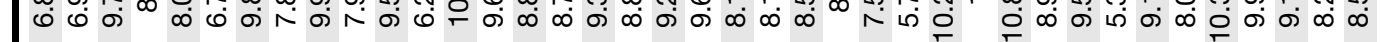

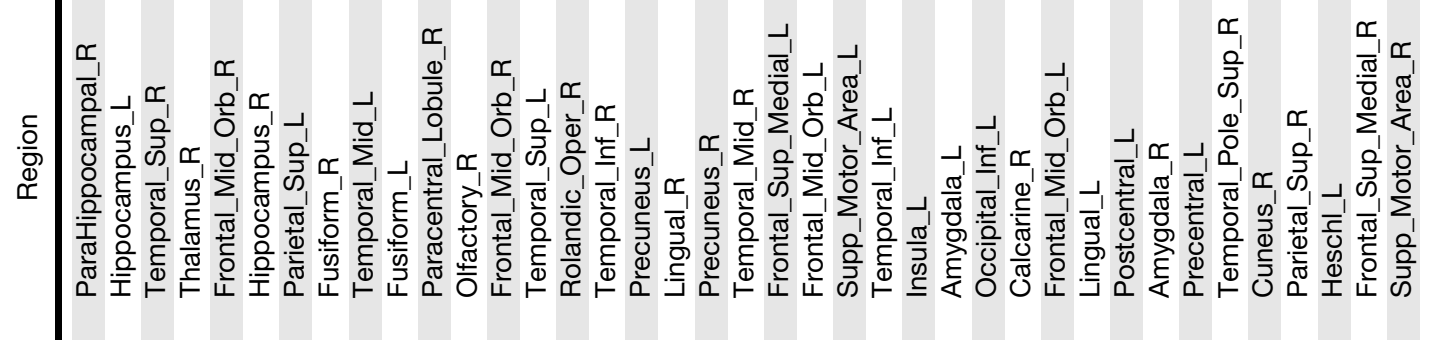


TABLE 3

Brain Regions That Did Not Survive FDR Analysis

\begin{tabular}{|c|c|c|c|c|c|}
\hline \multirow[b]{2}{*}{ Region } & \multicolumn{2}{|c|}{ Mean } & \multirow[b]{2}{*}{ Difference } & \multirow[b]{2}{*}{ Difference (\%) } & \multirow[b]{2}{*}{$P$ (2-tailed) } \\
\hline & $A D$ & Control & & & \\
\hline Occipital_Sup_L & $10.52(2.4)$ & $8.39(1.65)$ & 2.13 & 25.4 & 0.047 \\
\hline Cingulum_Mid_R & 7.7 (1.48) & $6.55(0.66)$ & 1.15 & 17.6 & 0.051 \\
\hline Thalamus_L & $8.21(1.77)$ & $6.95(0.56)$ & 1.26 & 18.1 & 0.060 \\
\hline Temporal_Pole_Sup_L & $7.99(2.24)$ & $6.38(1)$ & 1.61 & 25.3 & 0.069 \\
\hline Temporal_Pole_Mid_L & $9.17(2.58)$ & $7.41(1.21)$ & 1.76 & 23.7 & 0.087 \\
\hline Cingulum_Post_L & $7.75(1.71)$ & $6.64(0.61)$ & 1.11 & 16.7 & 0.087 \\
\hline Cingulum_Ant_R & $6.29(1.27)$ & $5.45(0.73)$ & 0.83 & 15.3 & 0.113 \\
\hline Pallidum_L 7021 & $6.69(1.49)$ & $5.83(0.66)$ & 0.86 & 14.8 & 0.136 \\
\hline Cingulum_Post_R & $7.45(2.39)$ & $6.17(0.58)$ & 1.28 & 20.7 & 0.140 \\
\hline Pallidum_R & $6.5(1.51)$ & $5.71(1.04)$ & 0.79 & 13.8 & 0.226 \\
\hline Caudate_R & $6.02(1.92)$ & $5.33(0.74)$ & 0.68 & 12.8 & 0.338 \\
\hline Caudate_L & $5.8(2.15)$ & $5.33(0.76)$ & 0.47 & 8.9 & 0.544 \\
\hline
\end{tabular}

Regions are as defined in stereotactic atlas of Tzourio-Mazoyer et al. (35). Data in parentheses are SD.

mation. This hypothesis was based on showing elevated brain $K^{*}$ for AA and other markers of AA metabolism in a rodent lipopolysaccharide-infusion model of neuroinflammation and on evidence of neuroinflammation associated with senile (neuritic) plaques surrounded by activated microglia and of accumulated $\beta$-amyloid in the AD brain. The distribution of senile plaques is more common in cortical than in subcortical brain regions $(41,42)$ and may explain why PVE-corrected $K^{*}$ for AA in the left thalamus and in bilateral caudate nucleus and pallidum did not survive the FDR analysis (Table 3; Fig. 1).

Comparing $K^{*}$ for AA with $\mathrm{rCBF}$ in this study was useful for several reasons. The ${ }^{15} \mathrm{O}$-water PET scan helped to coregister the $1-{ }^{11} \mathrm{C}$-AA PET scan with the subject's anatomic MRI scan, helping to identify regions in the $K^{*}$ images and to perform the PVE correction (32). $K^{*}$ 's independence of $\mathrm{rCBF}$ was confirmed by finding that PVE-corrected values for global and regional $K^{*}$ were elevated, whereas uncorrected global CBF was decreased and PVE-corrected rCBF tended to decrease. Flow independence of $K^{*}$ has been demonstrated in preclinical studies (17) and exists because the unesterified AA that is highly bound to circulating albumin acts as an "infinite" and rapidly available source of AA delivery to the brain (16).

The pattern of AD-related differences in $K^{*}$ for AA in this study might be compared with differences found with other relevant PET compounds. For example, brain uptake of ${ }^{11} \mathrm{C}-(R)-\mathrm{PK} 11195$, a ligand for peripheral benzodiazepine receptors on activated brain microglia, was increased in cortical but not in subcortical regions in patients with AD, compared with control subjects $(43,44)$, as was uptake of ${ }^{11} \mathrm{C}$-PIB, a ligand for $\beta$-amyloid (45). Comparisons with ${ }^{11} \mathrm{C}$-PIB imaging may be particularly important in the course of $\mathrm{AD}$, as $\beta$-amyloid peptide alone can stimulate cytokine formation and activate $\mathrm{PLA}_{2}$ before senile plaques

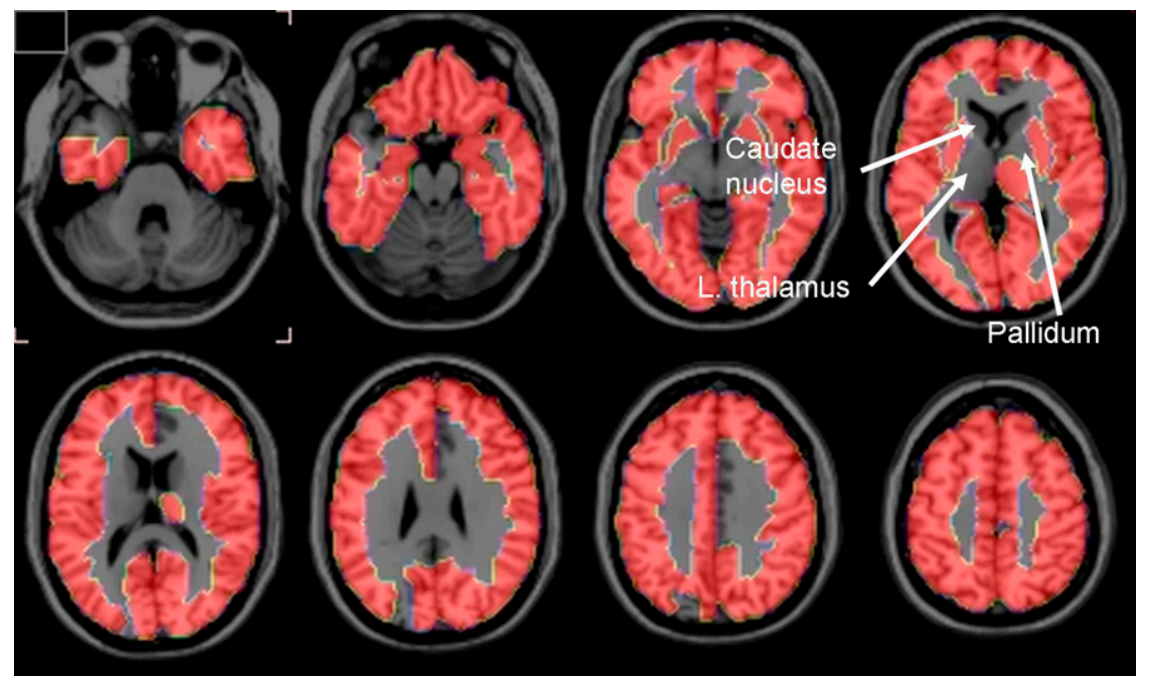

FIGURE 1. Horizontal brain slices showing brain regions in which PVEcorrected $K^{*}$ for AA survived FDR procedure that separated patients with $A D$ from control subjects at $5 \%$ level of significance. Regions in 1-mm-thick T1weighted MRI slices are defined in Tables 2 and 3 based on stereotactic atlas of Tzourio-Mazoyer et al. (35). 
accumulate $(9,10)$. Glucose metabolism, to which rCBF is coupled, is reduced in $\mathrm{AD}$ more in neocortical than in subcortical regions $(31,46)$.

The results of the current study should be considered preliminary. Future studies should include more subjects and perhaps consider additional methods (e.g., statistical parametric mapping, correlation approaches) to evaluate the data. Doing so should help to identify significant differences in $\mathrm{rCBF}$ and to relate $\mathrm{rCBF}$ and $K^{*}$ for $\mathrm{AA}$ in patients with $\mathrm{AD}$ to each other and to dementia severity. Individual metabolite-corrected input functions to calculate $K^{*}$ also should be used. We could not do this in the patients with $\mathrm{AD}$ and in 2 of the controls in this study, but comparable significant changes in $K^{*}$ using the average input function after correcting for plasma metabolites indicated that this did not affect our conclusions.

rCBF and $K^{*}$ for AA were analyzed after correcting for the PVE, to address the effect of atrophy and estimate actual parenchymal rates $(19,31)$. With this correction, the estimated tracer concentration in high-uptake areas is increased, which translates into a nonuniform increase in $K^{*}$ for AA or rCBF. Furthermore, the correction increases noise in the data (40). However, the results and the analyses of global values suggest that this correction did not affect group separation with $K^{*}$.

\section{CONCLUSION}

Regional PVE-corrected $K^{*}$ for AA, a measure of regional brain AA consumption, was elevated in widespread cortical areas of mildly to moderately (1 severely) demented but otherwise healthy patients with $\mathrm{AD}$, compared with age-matched controls. These results support the hypothesis that $K^{*}$ for AA would be elevated in $\mathrm{AD}$, which was based on evidence of upregulated markers of brain AA metabolism in a rat model of neuroinflammation and on the presence of neuroinflammation in AD. If such elevations are confirmed in follow-up studies on larger groups of patients and controls, we might then use intravenous $1{ }^{11} \mathrm{C}$ AA with PET to image the involvement of AA in neuroinflammation in $\mathrm{AD}$ and other brain diseases.

\section{ACKNOWLEDGMENTS}

We thank Dr. Madhav Thambisetty for his helpful comments about the manuscript. This work was supported by the Intramural Programs of the National Institute on Aging, the National Institute of Neurological Disorders and Stroke, the National Institute of Mental Health, and the PET Department of the Clinical Center at the National Institutes of Health, Bethesda, Maryland.

\section{REFERENCES}

1. Banati RB, Myers R, Kreutzberg GWPK. PK ('peripheral benzodiazepine')binding sites in the CNS indicate early and discrete brain lesions: microautoradiographic detection of $\left[{ }^{3} \mathrm{H}\right] \mathrm{PK} 11195$ binding to activated microglia. J Neurocytol. 1997;26:77-82.
2. Kreutzberg GW. Microglia: a sensor for pathological events in the CNS. Trends Neurosci. 1996;19:312-318.

3. McGeer PL, McGeer EG. Glial cell reactions in neurodegenerative diseases: pathophysiology and therapeutic interventions. Alzheimer Dis Assoc Disord. 1998;12(suppl 2):S1-S6.

4. Pahan K, Sheikh FG, Namboodiri AM, Singh I. Lovastatin and phenylacetate inhibit the induction of nitric oxide synthase and cytokines in rat primary astrocytes, microglia, and macrophages. J Clin Invest. 1997;100:2671-2679.

5. Sun GY, Horrocks LA, Farooqui AA. The roles of NADPH oxidase and phospholipases A2 in oxidative and inflammatory responses in neurodegenerative diseases. J Neurochem. 2007;103:1-16.

6. Dennis EA. Diversity of group types, regulation, and function of phospholipase A2. J Biol Chem. 1994;269:13057-13060.

7. Weichel O, Hilgert M, Chatterjee SS, Lehr M, Klein J. Bilobalide, a constituent of Ginkgo biloba, inhibits NMDA-induced phospholipase A2 activation and phospholipid breakdown in rat hippocampus. Naunyn Schmiedebergs Arch Pharmacol. 1999;360:609-615.

8. Basselin M, Chang L, Bell JM, Rapoport SI. Chronic lithium chloride administration attenuates brain NMDA receptor-initiated signaling via arachidonic acid in unanesthetized rats. Neuropsychopharmacology. 2006;31:1659-1674.

9. Mattson MP, Chan SL. Neuronal and glial calcium signaling in Alzheimer's disease. Cell Calcium. 2003;34:385-397.

10. Lehtonen JY, Holopainen JM, Kinnunen PK. Activation of phospholipase A2 by amyloid beta-peptides in vitro. Biochemistry. 1996;35:9407-9414.

11. Stephenson DT, Lemere CA, Selkoe DJ, Clemens JA. Cytosolic phospholipase $\mathrm{A}_{2}$ (cPLA $)$ immunoreactivity is elevated in Alzheimer's disease brain. Neurobiol Dis. 1996;3:51-63.

12. Bazan NG, Colangelo V, Lukiw WJ. Prostaglandins and other lipid mediators in Alzheimer's disease. Prostaglandins Other Lipid Mediat. 2002;68-69:197-210.

13. Greenamyre JT, Maragos WF, Albin RL, Penney JB, Young AB. Glutamate transmission and toxicity in Alzheimer's disease. Prog Neuropsychopharmacol Biol Psychiatry. 1988;12:421-430.

14. Montine KS, Quinn JF, Zhang J, et al. Isoprostanes and related products of lipid peroxidation in neurodegenerative diseases. Chem Phys Lipids. 2004;128: $117-124$.

15. DeMar JC Jr, Lee HJ, Ma K, et al. Brain elongation of linoleic acid is a negligible source of the arachidonate in brain phospholipids of adult rats. Biochim Biophys Acta. 2006;1761:1050-1059.

16. Robinson PJ, Noronha J, DeGeorge JJ, Freed LM, Nariai T, Rapoport SI. A quantitative method for measuring regional in vivo fatty-acid incorporation into and turnover within brain phospholipids: review and critical analysis. Brain Res Brain Res Rev. 1992;17:187-214.

17. Chang MCJ, Arai T, Freed LM, et al. Brain incorporation of $\left[1-{ }^{11} \mathrm{C}\right]-$ arachidonate in normocapnic and hypercapnic monkeys, measured with positron emission tomography. Brain Res. 1997;755:74-83.

18. Giovacchini G, Chang MC, Channing MA, et al. Brain incorporation of $\left[{ }^{11} \mathrm{C}\right]$ arachidonic acid in young healthy humans measured with positron emission tomography. J Cereb Blood Flow Metab. 2002;22:1453-1462.

19. Giovacchini G, Lerner A, Toczek MT, et al. Brain incorporation of ${ }^{11} \mathrm{C}$ arachidonic acid, blood volume, and blood flow in healthy aging: a study with partial-volume correction. J Nucl Med. 2004;45:1471-1479.

20. Rosenberger TA, Villacreses NE, Hovda JT, et al. Rat brain arachidonic acid metabolism is increased by a 6-day intracerebral ventricular infusion of bacterial lipopolysaccharide. J Neurochem. 2004;88:1168-1178.

21. Richardson RL, Kim EM, Gardiner T, O'Hare E. Chronic intracerebroventricular infusion of lipopolysaccharide: effects of ibuprofen treatment and behavioural and histopathological correlates. Behav Pharmacol. 2005;16:531-541.

22. Lee H, Villacreses NE, Rapoport SI, Rosenberger TA. In vivo imaging detects a transient increase in brain arachidonic acid metabolism: a potential marker of neuroinflammation. J Neurochem. 2004;91:936-945.

23. Lee HJ, Rao JS, Chang L, Rapoport SI, Bazinet RP. Chronic N-methyl-Daspartate administration increases the turnover of arachidonic acid within brain phospholipids of the unanesthetized rat. J Lipid Res. 2008;49:162-168.

24. Basselin M, Villacreses NE, Lee HJ, Bell JM, Rapoport SI. Chronic lithium administration attenuates up-regulated brain arachidonic acid metabolism in a rat model of neuroinflammation. J Neurochem. 2007;102:761-772.

25. Esposito G, Giovacchini G, Der M, et al. Imaging signal transduction via arachidonic acid in the human brain during visual stimulation, by means of positron emission tomography. Neuroimage. 2007;34:1342-1351.

26. Herscovitch P, Markham J, Raichle ME. Brain blood flow measured with intravenous $\mathrm{H}_{2}{ }^{15} \mathrm{O}$. I. Theory and error analysis. J Nucl Med. 1983;24:782-789.

27. Folstein MF, Folstein SE, McHugh PR. "Mini-Mental State": a practical method for grading the cognitive state of patients for the clinician. J Psychiatr Res. 1975;12:189-198. 
28. Channing MA, Simpson N. Radiosynthesis of 1-[11'C]polyhomoallylic fatty acids. J Labeled Compounds Radiopharmacol. 1993;33:541-546.

29. Belfrage P, Vaughan M. Simple liquid-liquid partition system for isolation of labeled oleic acid from mixtures with glycerides. J Lipid Res. 1969;10:341-344.

30. Brooks DJ, Lammertsma AA, Beaney RP, et al. Measurement of regional cerebral $\mathrm{pH}$ in human subjects using continuous inhalation of ${ }^{11} \mathrm{CO}_{2}$ and positron emission tomography. J Cereb Blood Flow Metab. 1984;4:458-465.

31. Ibanez V, Pietrini P, Alexander GE, et al. Regional glucose metabolic abnormalities are not the result of atrophy in Alzheimer's disease. Neurology. 1998;50: 1585-1593.

32. Jenkinson M, Smith S. A global optimisation method for robust affine registration of brain images. Med Image Anal. 2001;5:143-156.

33. Muller-Gartner HW, Links JM, Prince JL, et al. Measurement of radiotracer concentration in brain gray matter using positron emission tomography: MRIbased correction for partial volume effects. J Cereb Blood Flow Metab. 1992;12: 571-583.

34. Frackowiak RSJ, Friston KJ, Frith CD, et al. Human Brain Function. 2nd ed. San Diego, CA: Academic Press; 2004.

35. Tzourio-Mazoyer N, Landeau B, Papathanassiou D, et al. Automated anatomical labeling of activations in SPM using a macroscopic anatomical parcellation of the MNI MRI single-subject brain. Neuroimage. 2002;15:273-289.

36. Ibanez V, Pietrini P, Furey ML, et al. Resting state brain glucose metabolism is not reduced in normotensive healthy men during aging, after correction for brain atrophy. Brain Res Bull. 2004;63:147-154.

37. Benjamini Y, Hochberg Y. Controlling the false discovery rate: a practical and powerful approach to multiple testing. J Royal Statistical Soc Ser B. 1995;57:289-300.
38. Benjamini Y, Drai D, Elmer G, Kafkafi N, Golani I. Controlling the false discovery rate in behavior genetics research. Behav Brain Res. 2001;125: 279-284.

39. Jagust W. Cerebral blood flow and metabolism in dementia: regional patterns and the biology of Alzheimer's disease. Dev Brain Dysfunct. 1994;7:302-310.

40. Rousset OG, Ma Y, Evans AC. Correction for partial volume effects in PET: principle and validation. J Nucl Med. 1998;39:904-911.

41. DeCarli CS, Atack JR, Ball MJ, et al. Post-mortem regional neurofibrillary tangle densities but not senile plaque densities are related to regional cerebral metabolic rates for glucose during life in Alzheimer's disease patients. Neurodegeneration. 1992;1:113-121.

42. Giannakopoulos P, Hof PR, Mottier S, Michel JP, Bouras C. Neuropathological changes in the cerebral cortex of 1258 cases from a geriatric hospital: retrospective clinicopathological evaluation of a 10-year autopsy population. Acta Neuropathol (Berl). 1994;87:456-468.

43. Cagnin A, Brooks DJ, Kennedy AM, et al. In-vivo measurement of activated microglia in dementia. Lancet. 2001;358:461-467.

44. Versijpt JJ, Dumont F, Van Laere KJ, et al. Assessment of neuroinflammation and microglial activation in Alzheimer's disease with radiolabelled PK11195 and single photon emission computed tomography: a pilot study. Eur Neurol. 2003; 50:39-47.

45. Kemppainen NM, Aalto S, Wilson IA, et al. Voxel-based analysis of PET amyloid ligand $\left[{ }^{11} \mathrm{C}\right] \mathrm{PIB}$ uptake in Alzheimer disease. Neurology. 2006;67: 1575-1580.

46. Kumar A, Schapiro MB, Grady C, et al. High-resolution PET studies in Alzheimer's disease. Neuropsychopharmacology. 1991;4:35-46. 